\title{
Teknik Instruksional Pertanyaan Guru Di Tahap Evaluating Data, Driving A Conclusion, Presenting The Project In Class As Preffered \& Discussion Project Based Learning Untuk Meningkatkan Skor Valid Relationship Concept Map
}

\section{Instructional Techniques Teacher's Question on Evaluating Data, Driving a Conclusion, Presenting the Project in Class as Preffered and Discussion Stage of Project Based Learning to Increase Valid Relationship Concept Map Score}

\author{
Yacinta Arum Dwi Rahayu $^{1}$, Yudi Rinanto ${ }^{1}$, Sri Widoretno ${ }^{1 *}$ \\ ${ }^{1}$ Pendidikan Biologi FKIP UNS, Jl. Ir. Sutami No.36A Jebres, Surakarta, Indonesia \\ *Corresponding author: sriwidoretno@staff.uns.ac.id
}

Abstract: This research aimed to calculate the valid relationship score of concept map (CM) using instructional technique of teacher's questions in the stages of evaluating data, driving a conclusion, presenting the project in class as preferred \& discussion project-based learning. This research was a classroom action research. This research was a classroom action research with the research subject of 36 students in X MIPA of Senior High School. The research procedure was including: planning, lesson plan completed with assessment, acting, observing and reflecting. Validity test in this research was using triangulation method that consisted of verification of valid relationship $\mathrm{CM}$ score, documentation based on expert $\mathrm{CM}$ and interview to present the valuable relation between concepts. Reduction done to choose the data completion, data interpretation and conclusion based on the complete valid relationship data. Data analysis was using descriptive qualitative. The result of this research shows that valid relationship score of expert CM in pre-research, cycle I and cycle II were written as follows. $1.95 \%-14.98 \%$ with $13.89 \%$ of the under averaged students' score and $11.11 \%$ of the over averaged students' score. $3.08 \%-61.54 \%$ with $19.44 \%$ of the under averaged students' score and $11.11 \%$ of the over averaged students' score. $16.58 \%-32.16 \%$ with $11.11 \%$ of the under averaged students' score and $16.67 \%$ of over averaged students' score. Thus, the use of instructional technique of questioning in the stages of evaluating data, driving a conclusion, presenting the project in class as preferred $\&$ discussion project-based learning improving the valid relationship CM score on the individual and classical.

Keywords: Instructional technique, concept map, valid relationship, project-based learning

\section{PENDAHULUAN}

Concept map merupakan bentuk grafis yang merepresentasikan hubungan antar konsep (Tribuzi, 2015) serta membantu peserta didik memahami konsep yang dimiliki dalam ingatan jangka panjang (Rye, \& Rubba, 1998). Concept map memiliki komponen yang meliputi, crosslink hierarki branching, pattern, example dan valid relationship (Vanides, Yin, \& Tomita, 2005). Valid relationship diwakili dengan sebuah garis yang menghubungkan dua konsep (Cronin, Dekhers, \& Dunn, 1982). Dua konsep dan hubungannya membentuk sebuah proposisi (Strautmane, 2012). Valid relationship merepresentasikan kemampuan peserta didik menghubungkan antar konsep (Novak \& Cañas, 2008).

Konsep tidak mampu dijelaskan tanpa mengacu hubungan antar konsep (Ruiz Primo \& ShaVelson, 1996), yang terukur melalui skor valid relationship pada concept map. Concept map merupakan teknik instruksional sekaligus assessment (Stoddart, 2006) berupa produk di akhir pembelajaran (McClure, Sonak, \& Suen, 1999), namun dari hasil observasi, concept map belum dijadikan sebagai produk dalam pembelajaran, sehingga valid relationship yang merupakan hubungan antar konsep belum tervisualisasi.

Valid relationship pada concept map merupakan produk pembelajaran yang diakomodasi dengan model pembelajaran project based learning (Kean \& 
Kwe, 2014). Project based learning terdiri dari 5 tahap, yaitu: planning an investigation process according to driving question, searching for the theoretical background of the driving question, presenting that theoretical background to class and discussion about issue, deciding the study group the $w$ ay of collecting data and data analysis, dan evaluating data, arriving a conclusion, presenting the project in class as preferred and discussion (Turgut, 2008).

Hasil observasi untuk $V R$ pada $C M$ dengan penerapan pembelajaran project based learning menunjukkan rata-rata skor adalah $8.31 \%$ dari total skor $100 \%$. Rentang skor untuk $V R$ pada $C M$ yang diperoleh peserta didik adalah $1.95 \%-14.98 \%$ dengan demikian pembelajaran project based learning secara murni menunjukkan bahwa skor $V R$ kurang optimal. Optimalisasi skor $V R$ peserta didik yang memvisualisasikan hubungan antar konsep dalam concept map pada project based learning dilakukan dengan penambahan teknik intruksional (Baumgartner \& Zabin, 2008).

Teknik instruksional membantu peserta didik fokus dalam proses pembelajaran (Dack, Hover, \& Hicks, 2015), salah satunya adalah arahan berupa pertanyaan yang digunakan guru untuk berinteraksi serta memfokuskan peserta didik pada konsep yang dipelajari (Al-Zahrani \& Al-Bargi, 2017). Teknik instruksional mampu diterapkan dalam semua tahap pembelajaran project based learning (Gustafson \& Branch, 2002) karena mengakomodasi peserta didik untuk mempresentasikan dan mengevaluasi hasil produk semua kelompok melalui diskusi kelas pada tahap evaluating data, arriving a conclusion, presenting the project in class as preferred and discussion (Turgut, 2008).

Tahap evaluating data, arriving a conclusion, presenting the project in class as preferred and discussion peserta didik mengalami kesulitan dalam memahami seluruh konten yang disajikan semua kelompok saat kegiatan presentasi hasil produk (Thomas, 2000), sehingga dibutuhkan penerapan teknik instruksional berupa pertanyaan guru (Weizman, Shwartz \& Fortus, 2008).

Pertanyaan guru memfokuskan peserta didik untuk menyusun jawaban dalam bentuk list, dengan demikian mempermudah untuk mengorganisasi konsep dalam bentuk concept map yang di dalamnya terdapat valid relationship (Cañas \& Novak, 2012). Teknik instruksional concept map berupa list membantu peserta didik untuk mengorganisasi dan menghubungkan antar konsep yang terlihat pada valid relationship (Thomas, 2005). Teknik instruksional pertanyaan guru pada tahap evaluating data, arriving a conclusion, presenting the project in class as preferred and discussion diasumsikan mampu meningkatkan skor valid relationship concept map peserta didik, dengan demikian tujuan penelitian yaitu meningkatkan skor valid relationship peserta didik dengan menerapkan teknik instruksional pertanyaan guru pada tahap evaluating data, driVing a conclusion, presenting the project in class as preffered \& discussion pembelajaran project based learning.

\section{METODE PENELITIAN}

Subjek penelitian adalah 36 peserta didik kelas $\mathrm{X}$ MIPA SMA yang terdiri dari 24 peserta didik perempuan dan 12 peserta didik laki-laki. Pemilihan subjek penelitian didasarkan pada permasalahan yang teridentifikasi pada kegiatan observasi selama proses pembelajaran yang berkaitan dengan semua pendukung skor concept map khususnya skor valid relationship.

Penelitian menggunakan model project based learning dengan penambahan teknik instruksional pertanyaan guru pada tahap evaluating data, arriving a conclusion, presenting the project in class as preferred and discussion. Materi yang digunakan pada prasiklus, siklus I dan siklus II berturut-turut adalah Musci, Anthocerophyta, dan Marchantiophyta. Data penelitian berupa skor VR pada $C M$ peserta didik dengan data pendukung keterlaksanaan sintak penerapan teknik instruksional di tahap evaluating data, arriving a conclusion, presenting the project in class as preferred and discussion, wawancara dan dokumentasi. Uji validitas data penelitian menggunakan teknik triangulasi data. Analisis data penelitian dilakukan dengan teknik analisis deskriptif kualitatif yang terdiri dari reduksi data untuk memilih data yang lengkap, penyajian data dan penarikan kesimpulan berdasarkan skor valid relationship yang lengkap. Analisis perhitungan skor valid relationship pada $C M$ sesuai dengan expert valid relationship CM. Contoh $C M$ menurut Novak \& Gowin (1984) ditunjukkan pada Gambar 1.

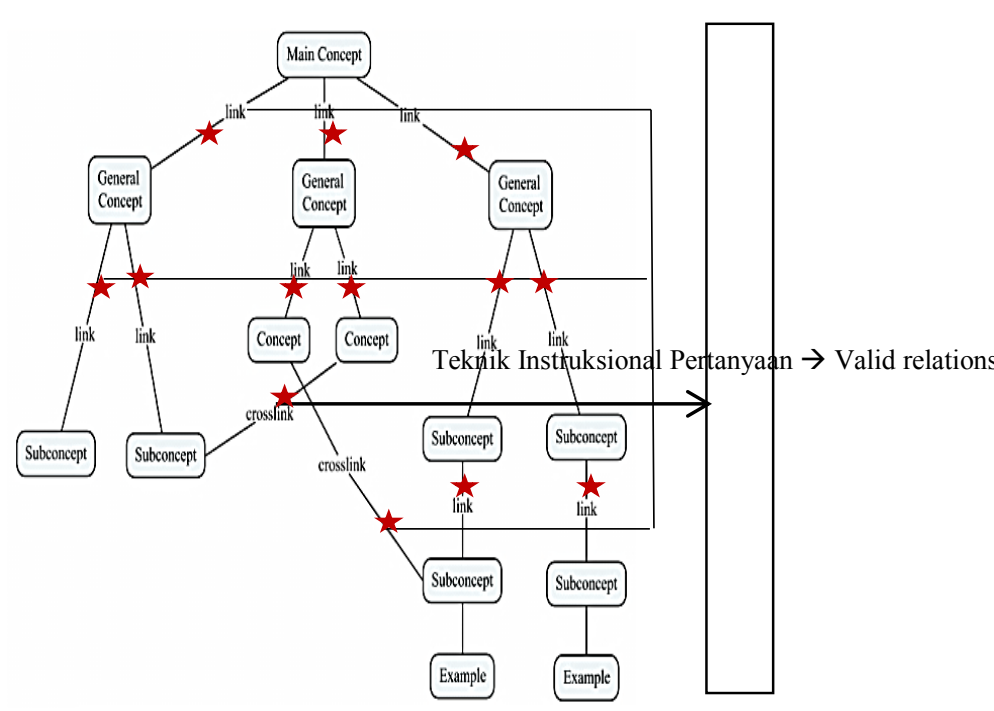

Gambar 1. Contoh $C M$ menurut Novak \& Gowin (1984)

Gambar 1 menunjukkan contoh $C M$ terdiri dari 13 valid realtionship. Penilaian skor $V R$ pada $C M$ 
menurut Novak \& Gowin (1984) disajikan pada Tabel 1.

$\underline{\text { Tabel 1. Penilaian skor } V \text { pada } C M \text { sesuai gambar } 1 .}$

\begin{tabular}{cccr}
\hline No & Indikator & Skor & Skor Expert VR \\
\hline 1. & Valid relationship $*$ & 1 poin & $1 \times 13=13$ poin \\
\hline \multicolumn{3}{c}{ Jumlah Skor } & 13 poin \\
\hline (Sumber: NoVak \& Gowin, 1984)
\end{tabular}

\section{HASIL DAN PEMBAHASAN}

\section{Hasil Penelitian}

Hasil penelitian berupa skor $V R C M$ peserta didik pada prasiklus, siklus I, siklus II dan perbandingan prasiklus-siklus II disajikan sebagai berikut:

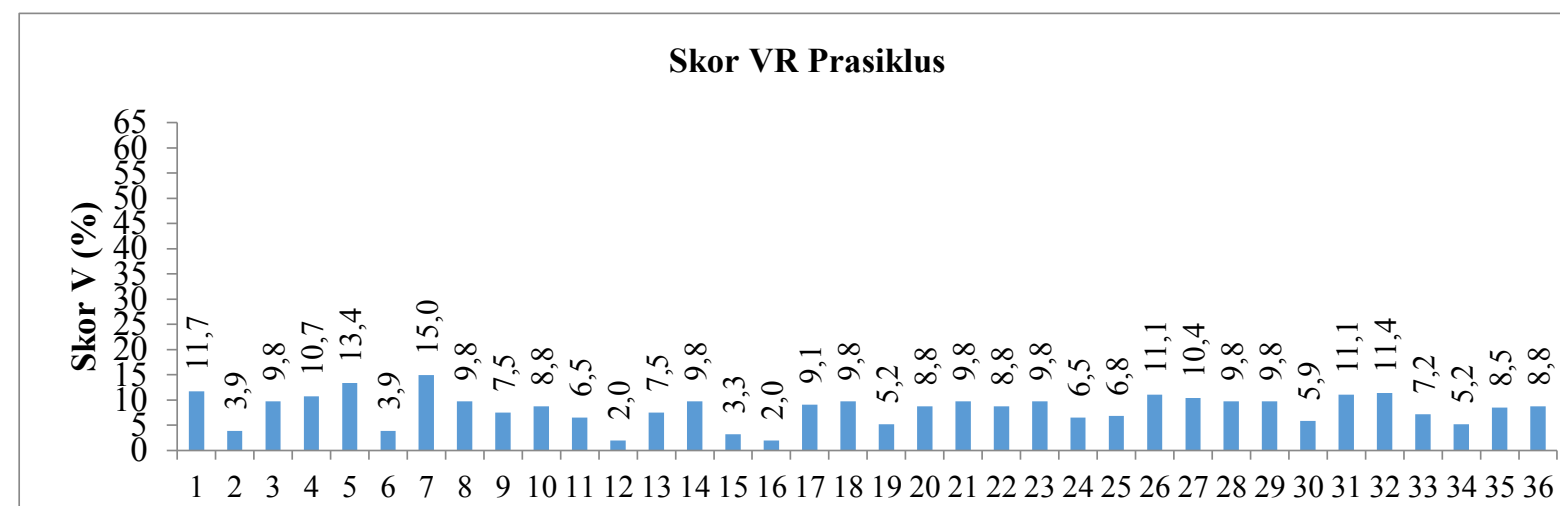

Nomor Presensi

Gambar 2. Prosentase Skor VR CM Peserta Didik Pada Prasiklus

Prasiklus dilaksanakan melalui kegiatan pembelajaran project based learning dengan materi Musci pada salah satu kelas X MIPA. Akhir dari kegiatan pembelajaran dilakukan dengan menyusun CM Musci menggunakan kertas dan pensil / bolpoint (Tsai, Lin, \& Yuan, 2001). Pembelajaran project based learning di salah satu kelas X MIPA pada materi Musci. Kegiatan pembelajaran diakhiri dengan menyusun $C M$. Hasil skor rata-rata $V R$ sebesar $8,31 \%$. Peserta didik yang memperoleh skor $V R$ di bawah rata-rata sebesar $13,89 \%$, sementara skor $V R$ di atas rata-rata sebesar $11,11 \%$ dari total peserta didik, dengan demikian analisis skor $V$ pada $C M$ yang telah dibuat peserta didik di akhir pembelajaran project based learning belum maksimal.

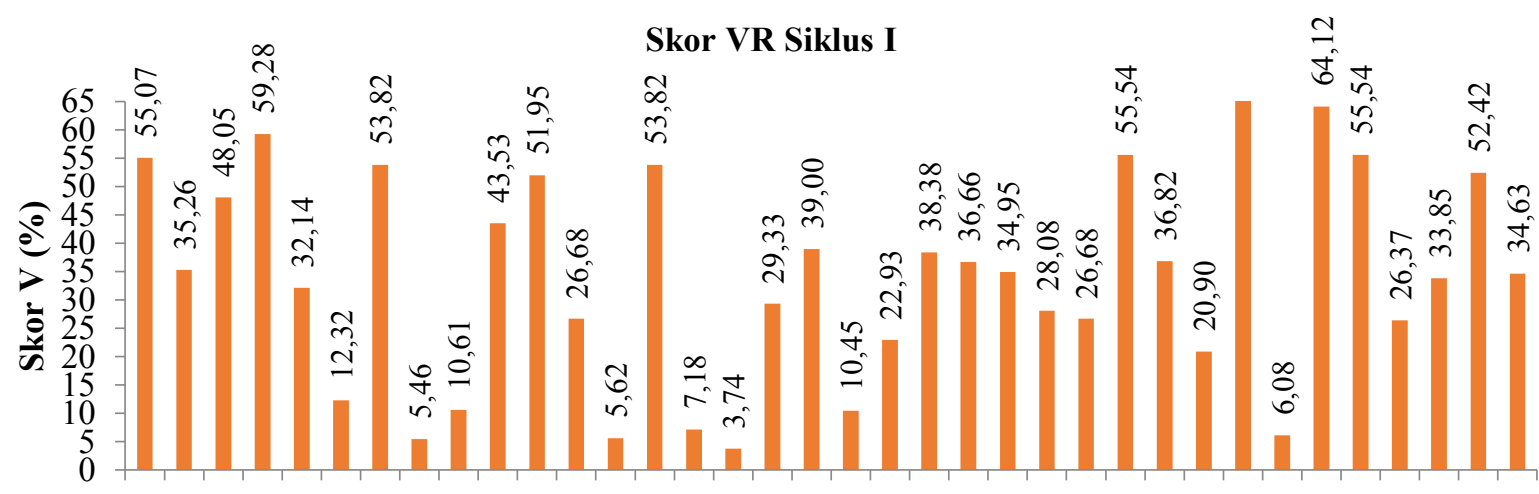

$1 \quad 2 \quad 3 \quad 4 \quad 5 \quad 6 \quad 7 \quad 8 \quad 9101112131415161718192021222324252627282930313233343536$

Nomor Presensi

Siklus I dilaksanakan melalui kegiatan pembelajaran project based learning dengan penambahan teknik instruksional berupa pertanyaan guru khususnya di tahap evaluating data, driving a conclusion, presenting the project in class as preffered \& discussion dengan materi Anthoceropyhta. Hasil skor rata-rata VR pada siklus I eserta Didik Pada Siklus I

sebesar $32.14 \%$. Peserta didik yang memperoleh skor $V R$ di bawah rata-rata sebesar 19,44\%, sementara skor $V R$ di atas rata-rata sebesar $11,11 \%$ dari total peserta didik, dengan demikian analisis skor $V R$ pada $C M$ yang telah dibuat peserta didik menunjukkan peningkatan dari prasiklus ke siklus I. 


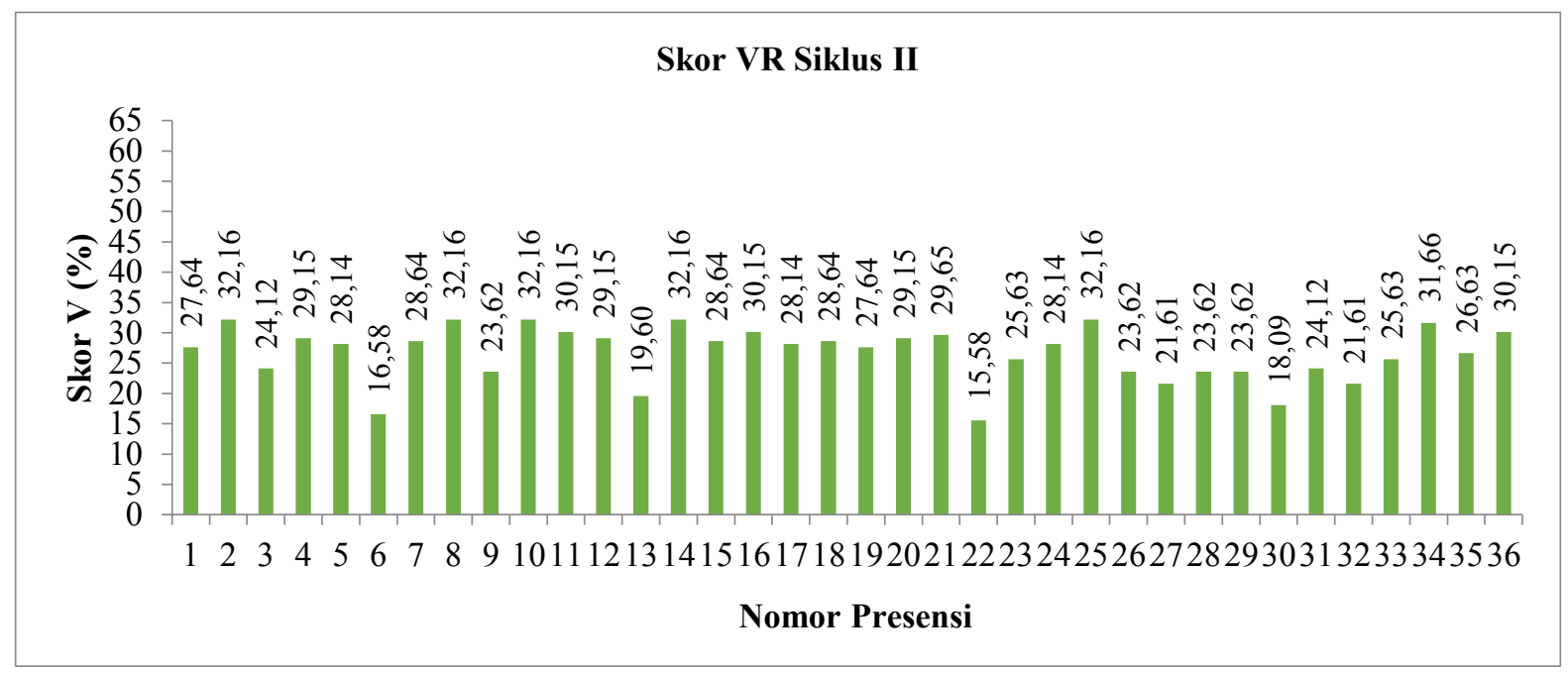

Gambar 2. Skor VR CM Peserta Didik Pada Siklus II

Siklus II dilaksanakan melalui kegiatan pembelajaran project based learning dengan penambahan teknik instruksional pertanyaan guru yang lebih detail dan fokus khususnya di tahap evaluating data, driving a conclusion, presenting the project in class as preffered \& discussion dengan materi Marchantiophyta. Hasil skor rata-rata $V R$ pada siklus II sebesar 26,65\%. Peserta didik yang memperoleh skor $V R$ di bawah rata-rata sebesar $11,11 \%$, sementara skor $V R$ di atas rata-rata sebesar $16,67 \%$ dari total peserta didik, dengan demikian analisis skor $V R$ pada $C M$ yang telah dibuat peserta menunjukkan peningkatan.

\section{Pembahasan berdasarkan Perbandingan Seluruh Siklus}

Prosentase skor $V R C M$ setiap peserta didik diperoleh berdasarkan evaluasi dalam pembelajaran prasiklus sampai dengan siklus II yang disajikan pada Gambar 5 sebagai berikut:

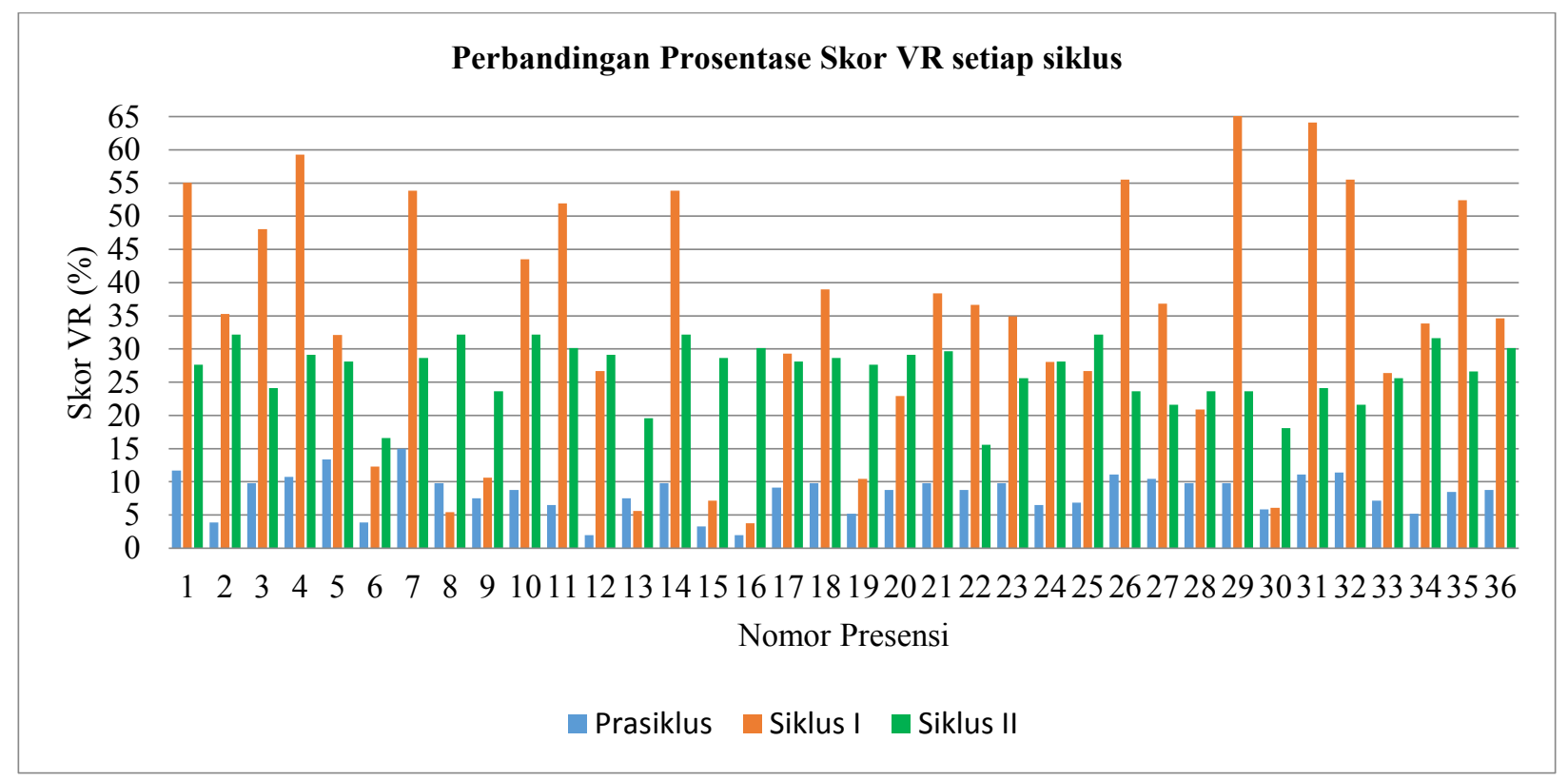

Gambar 5. Perbandingan Prosentase skor VR CM peserta didik di setiap siklus

$C M$ memiliki komponen yang meliputi $C, H, B$, $P, E$ dan $V R$ (Vanides, Yin, \& Tomita, 2005). Komponen $V R$ merepresentasikan kemampuan menghubungkan konsep peserta didik (Novak \&
Cañas, 2008). Valid relationship diwakili dengan sebuah garis yang menghubungkan dua konsep (Cronin, Dekhers, \& Dunn, 1982). Dua konsep dan hubungannya membentuk sebuah proposisi (Strautmane, 2012). Prosentase skor VR CM peserta 
didik pada setiap siklus secara umum memiliki variasi yang berbeda. Perbandingan hasil tindakan penerapan teknik instruksional di tahap evaluating data, driving a conclusion, presenting the project in class as preffered \& discussion pada project based learning mengalami fluktuasi rata-rata skor $V R C M$ setiap siklus dari prasiklus, siklus I dan siklus II berturut-turut sebesar $8.31 \%, 32.14 \%$, dan $26.65 \%$.

Total peserta didik yang memperoleh $V R$ di bawah rata-rata standar adalah $13.89 \%$ pada prasiklus, meningkat menjadi $19.44 \%$ pada siklus I dan menurun menjadi $11.11 \%$ pada siklus II. Total peserta didik yang memperoleh $V R$ normal adalah $75 \%$ pada prasiklus, menurun menjadi $69.44 \% \%$ pada siklus I dan meningkat menjadi $72.22 \%$ pada siklus II. Total peserta didik yang memperoleh $V R$ di atas rata-rata standar adalah $11.11 \%$ pada prasiklus, tetap pada siklus I $11.11 \%$ dan meningkat menjadi $16.67 \%$ pada siklus II.

Skor secara individu mengalami peningkatan untuk komponen $V R$ sebesar $94.44 \%$ dari prasiklus ke siklus I dan $36.11 \%$ dari siklus I ke siklus II. Skor VR CM yang meningkat dikarenakan penambahan teknik instruksional pertanyaan guru di tahap evaluating data, driving a conclusion, presenting the project in class as preffered \& discussion project based learning. Pertanyaan guru memfokuskan peserta didik untuk menyusun jawaban dalam bentuk list, dengan demikian mempermudah untuk mengorganisasi konsep dalam bentuk concept map (Cañas \& NoVak, 2012).

Teknik instruksional concept map berupa list membantu peserta didik untuk mengorganisasi dan menghubungkan antar konsep (Thomas, 2005), sehingga skor $V R$ mengalami peningkatan karena komponen $V R$ menunjukan kemampuan peserta didik dalam menghubungkan antar konsep (NoVak \& Cañas, 2008). Penurunan skor $V R$ dari siklus I ke siklus II disebabkan oleh waktu yang dihabiskan peserta didik untuk merevisi dan mempertahankan $C M$, dengan demikian peserta didik tidak fokus pada keseluruhan dari konsep (Tsai et al., 2001), sehingga waktu habis sebelum peserta didik mampu menghubungkan antar konsep. Pengaruh lain penurunan skor $V R$ dikarenakan peserta didik menyusun $C M$ menggunakan kertas dan pensil, sehingga kesulitan dalam konstruksi konsep yang rumit terutama bagi peserta didik yang awam dengan $C M$ (Tsai et al., 2001).

\section{SIMPULAN}

Hasil analisis penambahan teknik instruksional pertanyaan guru pada tahap tahap evaluating data, driving a conclusion, presenting the project in class as preffered \& discussion project based learning meningkatkan skor valid relationship CM secara individu maupun klasikal

\section{UCAPAN TERIMAKASIH}

Terimakasih kepada Tuhan Yang Maha Esa yang telah memberikan kekuatan kepada penulis dalam menyelesaikan jurnal ini. Terimaksih pula kepada Kepala Sekolah SMA N 1 Sragen, guru biologi SMA N 1 Sragen, Bapak Saifudin yang telah membantu dalam penelitian ini, semua partisipan dalam penelitian, keluarga, saudara serta teman-teman yang telah memberi dukungan dalam proses penelitian hingga penuyunan jurnal ini.

\section{DAFTAR PUSTAKA}

Al-Zahrani, M. Y., \& Al-Bargi, A. (2017). The Impact Of Teacher Questioning On Creating Interaction In Efl: A Discourse Analysis. English Language Teaching, 10(6), 135. Https://Doi.Org/10.5539/Elt.V10n6p135

Baumgartner, E., \& Zabin, C. J. (2008). A Case Study Of Project-Based Instruction In The Ninth Grade: A Semester- Long Study Of Intertidal BiodiVersity. EnVironmental Education Research, 14(2), 97-114. Https://Doi.Org/10.1080/13504620801951640

Broggy, J., \& McClelland, G. (2008). An InVestigation to Determine the Impact of Concept Mapping on Learning in an Undergraduate Physics Course. HE Academy Communication, 1(4), 34-38. https://doi.org/10.11120/ndir.2008.00040034

Cañas, A. J., \& NoVak, J. D. (2006). Re-examining the foundations for effectiVe use of concept maps. Concept Maps: Theory, Methodology, Technology; Proceedings of the Second International Conference on Concept Mapping, I, 494-502.

Cañas, A. J., \& NoVak, J. D. (2008). Facilitating the Adoption of Concept Mapping Using CmapTools to Enhance Meaningful Learning. Knowledge Cartography, Software Tools and Mapping Techniques, 1-26. https://doi.org/10.1007/978-1-84800-149-7_2

Cañas, A. J., NoVak, J. D., \& Reiska, P. (2012). Freedom Vs. Restriction of Content and Structure during Concept Mapping Possibilities and Limitations for Construction and Assessment. Concept Maps: Theory, Methodology, Technology. Proc. of the Fifth Int. Conference on Concept Mapping, 2(1), 247257. RetrieVed from http://eprint.ihmc.us/245/

Cronin, P. J., Dekhers, J., \& Dunn, J. G. (1982). A procedure for using and eValuating concept maps. Research in Science Education, 12(1), 17-24. https://doi.org/10.1007/BF02357009

Dack, H., HoVer, S. Van, \& Hicks, D. (2015). The Journal of Social Studies Research " Try Not to Giggle if You Can Help It ": The implementation of experiential instructional techniques in social studies classrooms \$. The Journal of Social Studies Research, 1-14. https://doi.org/10.1016/j.jssr.2015.04.002 
Doppelt, Y. (2003). Implementation and assessment of project-based learning in a flexible enVironment. International Journal of Technology and Design Education, 13(3), 255272. https://doi.org/10.1023/A:1026125427344

Gustafson, K. L., \& Branch, R. M. (2002). What is instructional design? Trends and Issues in Instructional Design and Technology. https://doi.org/10.1016/B978-0-12-386531$1.00002-8$

Illeris, K. (2009). Contemporary theories of learning. ... Exhibitions for Lifelong Learning. https://doi.org/10.1037/h0039426

Jim Vanides, Yue Yin, Miki Tomita, and M. A. R.P. (2005). Science Classroom. Science Scope, 28(8), 27-31.

Kean, A. C., \& Kwe, N. M. (2014). Meaningful Learning in the Teaching of Culture: The Project Based Learning Approach. Journal of Education and Training Studies, 2(2), 189-197. https://doi.org/10.11114/jets.V2i2.270

Bachri, B. S., Pendidikan, T., \& Pendidikan, F. I. (1986). MEYAKINKAN VALIDITAS DATA MELALUI TRIANGULASI PADA PENELITIAN KUALITATIF.

Baumgartner, E., \& Zabin, C. J. (2008). A case study of project-based instruction in the ninth grade: a semester-long study of intertidal biodiVersity. EnVironmental Education Research, 14(2), 97114. https://doi.org/10.1080/13504620801951640

Bimbingan, B., \& Konseling, D. A. N. (2016). METODE PENELITIAN KUALITATIF DALAM, 2(2).

Cronin, P. J., Dekhers, J., \& Dunn, J. G. (1982). A procedure for using and eValuating concept maps. Research in Science Education, 12(1), 17-24. https://doi.org/10.1007/BF02357009

Dack, H., HoVer, S. Van, \& Hicks, D. (2015). The Journal of Social Studies Research "Try Not to Giggle if You Can Help It ": The implementation of experiential instructional techniques in social studies classrooms \$. The Journal of Social Studies Research, 1-14. https://doi.org/10.1016/j.jssr.2015.04.002

Gustafson, K. L., \& Branch, R. M. (2002). What is instructional design? Trends and Issues in Instructional Design and Technology. https://doi.org/10.1016/B978-0-12-3865311.00002-8

Jim Vanides, Yue Yin, Miki Tomita, and M. A. R.P. (2005). Science Classroom. Science Scope, 28(8), 27-31.

NoVak, J. D., \& Cañas, a J. (2008). The Theory Underlying Concept Maps and How to Construct and Use Them. IHMC CmapTools, 136. https://doi.org/Technical Report IHMC CmapTools 2006-01 ReV 2008-01

Strautmane, M. (2012). Concept Map-Based Knowledge Assessment Tasks and their Scoring Criteria: an OVerView. Concept Maps: Theory, Methodology, Technology. Proc. of the Fifth Int.
Conference on Concept Mapping, 1, 80-88. RetrieVed from http://eprint.ihmc.us/219/

Tsai, C. C., Lin, S. S. J., \& Yuan, S. M. (2001). Students' use of web-based concept map testing and strategies for learning. Journal of Computer Assisted Learning, 17(1), 72-84. https://doi.org/10.1046/j.13652729.2001.00160.x

Turgut, H. (2008). PROSPECTIVE SCIENCE TEACHERS , CONCEPTUALIZATIONS ABOUT PROJECT BASED, 1(1). 